\title{
Strengthening union level facility for providing normal delivery and newborn care services: Facility assessment report
}

Md. Noorunnabi Talukder

Ubaidur Rob

Population Council

A.K.M. Zafar Ullah Khan

Amar Krishna Baidya

M. Mostafizur Rahman Khan

See next page for additional authors

Follow this and additional works at: https://knowledgecommons.popcouncil.org/departments_sbsr-rh

Part of the Demography, Population, and Ecology Commons, Family, Life Course, and Society Commons, International Public Health Commons, and the Medicine and Health Commons How does access to this work benefit you? Let us know!

\section{Recommended Citation}

Talukder, Md. Noorunnabi, Ubaidur Rob, A.K.M. Zafar Ullah Khan, Amar Krishna Baidya, M. Mostafizur Rahman Khan, and Nargis Sultana. 2011. "Strengthening union level facility for providing normal delivery and newborn care services: Facility assessment report." Dhaka: Population Council. 


\section{Authors}

Md. Noorunnabi Talukder, Ubaidur Rob, A.K.M. Zafar Ullah Khan, Amar Krishna Baidya, M. Mostafizur Rahman Khan, and Nargis Sultana 
Strengthening Union Level Facility for Providing Normal Delivery and Newborn Care Services

Facility Assessment Report 


\title{
Strengthening Union Level Facility for Providing Normal Delivery and Newborn Care Services
}

Facility Assessment Report

\author{
Md. Noorunnabi Talukder \\ Ubaidur Rob \\ A.K.M. Zafar Ullah Khan \\ Amar Krishna Baidya \\ M. Mostafizur Rahman Khan \\ Nargis Sultana \\ Population Council, Bangladesh
}

April 2011 


\section{ACKNOWLEDGEMENTS}

The Council expresses its sincere gratitude to DFID/Bangladesh for their interest and financial contribution in carrying out the situation analysis under the policy and systems research study on Health and Family Welfare Center (HFWC). We sincerely thank Dr. Shehlina Ahmed, Health and Population Advisor, DFID for her insights and support in implementing the policy and systems research study.

The Council gratefully acknowledges the cooperation of Civil Surgeons and Deputy DirectorsFamily Planning of Kustia, Khulna, Kurigram, Gaibandha, Sunamgonj, Habigonj, Laxmipur and Brahmanbaria district in carrying out the facility assessment study. We are grateful to the managers and service providers of the health facilities participated at the assessment.

We are indebted to Dr. Jafar Ahmad Hakim, Consultant to Population Council and former Director, Maternal and Child Health, Directorate General of Family Planning for his continued technical assistance in implementing the assessment study.

Finally, special thanks go to Population Council colleagues for technical, administrative and logistical support. 


\section{CONTENTS}

Acknowledgements $\quad$ iii

I Introduction 1

II Objective 1

III Methodology 1

IV Findings from Situation Analysis 4

Physical infrastructure $\quad 4$

Human resources $\quad 8$

$\begin{array}{ll}\text { Gaps in service delivery } & 10\end{array}$

V Findings from In-depth Interviews $\quad 12$

$\begin{array}{ll}\text { Experience and opinions of FWVs } & 12\end{array}$

$\begin{array}{ll}\text { Experience and opinions of Managers } & 15\end{array}$

VI Conclusion 19 


\section{INTRODUCTION}

In rural areas in Bangladesh, first level fixed-facility services are provided at the union level (the lowest administrative unit covering about 30,000 population) through a Health and Family Welfare Center (HFWC). These union-level health facilities (HFWC is used interchangeably) are designed to improve maternal and child health by making services available to the people in rural areas. However, most of the HFWCs do not have the capacity to provide normal delivery services. HFWCs could help women to receive free normal delivery services within a convenient distance from their home, if strengthened with necessary human resources, infrastructure and equipment. The existing infrastructure would need to be strengthened for providing those services, for which situation analysis is required.

In this situation, Population Council, with financial assistance from DFID, carried out a policy and systems research study with the purpose of seeking evidence to strengthen the union HFWCs for providing normal delivery and newborn care services in rural areas of Bangladesh. This study is expected to develop a framework for enabling the required improvements at the HFWC to offer normal delivery services. Towards this end, policy advocacy and situation analysis activities were undertaken. As part of policy advocacy activities, a series of workshops and consultative meetings regarding HFWC were organized.

In line with the study design and the key recommendations from the HFWC national workshop, situation analysis of HFWCs was conducted to assess readiness of facilities in terms of human resources, infrastructure and referral mechanism for providing normal delivery and newborn care services. From a list of districts with upazilas and unions, a total of 24 HFWCs were systematically selected and visited for collecting necessary information. Situation analysis was started on 22 February 2011 and continued through the end of March 2011.

\section{OBJECTIVE}

The main objective of the assessment was to know the present conditions of the HFWC regarding infrastructure, human resources, and equipment and supplies, and also to identify the needs to be able to provide normal delivery services.

\section{METHODOLOGY}

To assess the readiness of the facilities for providing normal delivery and newborn care services, data were collected through health facility assessment and in-depth interviews with managers and service providers.

\section{Health Facility Assessment}

Health Facility Assessment (HFA) was conducted in order to have reliable information on available health resources and their conditions at union level facilities. The facility survey was designed to collect detailed information on the availability of human resources, the availability and condition of 
the physical assets, and physical access. It also covered limited dimensions of quality of services. HFA serves as a baseline for increasing investment into the facility.

\section{Sampling population}

A systematic process was employed to select HFWCs for situation analysis. Data were collected from 24 union-level facilities from four divisions. To begin with, two high-performing and two lowperforming divisions were selected purposively. Khulna and Rangpur divisions were selected as high-performing areas, and Sylhet and Chittagong divisions as low-performing areas. From each division two districts were selected at random, and then two upazilas were randomly selected from each district. Thus, a total of 16 upazilas were selected, from which 24 HFWCs were selected for the situation analysis study. Distribution of divisions and districts is presented in Table 1.

\section{Table 1 Distribution of divisions and districts}

\begin{tabular}{|l|l|}
\hline Division & District \\
\hline Khulna & $\begin{array}{l}\text { Kustia } \\
\text { Khulna }\end{array}$ \\
\hline Rangpur & $\begin{array}{l}\text { Kurigram } \\
\text { Gaibandha }\end{array}$ \\
\hline Sylhet & $\begin{array}{l}\text { Sunamgonj } \\
\text { Habigonj }\end{array}$ \\
\hline Chittagong & $\begin{array}{l}\text { Laxmipur } \\
\text { Brahmanbaria }\end{array}$ \\
\hline
\end{tabular}

The distribution of unions by upazila varied. In the first stage, one union was selected from each upazila. In the later stage, another union was selected from an alternate upazila. Thus, eight upazilas had two unions each and remaining eight upazilas had one union. In selecting unions, the types of HFWCs were considered too. It is worth noting that there are three types of HFWCs in terms of physical infrastructure: one storied, two-storied, and three storied. A probability proportional to size (PPS) sampling technique was employed to select samples of sites. The number and types of facilities that were assessed for readiness of normal delivery services are shown in Table 2.

\section{Table 2 Number of facilities visited}

\begin{tabular}{|l|r|}
\hline Types of facility & Number \\
\hline One-storied & 9 \\
\hline Two-storied & 11 \\
\hline Three-storied & 4 \\
\hline Total & 24 \\
\hline
\end{tabular}




\section{Data collection}

The data collection was carried out by researchers of the Population Council after necessary orientation had been provided to them on substantive, quality and ethical issues. The Council developed the data collection tools. The process of developing the data collection tools included review of similar tools and expert opinion.

The facility assessment measured a set of standard indicators of service readiness and quality. These indicators captured information essential for the needs assessment and planning investment in the union health facility. The facility assessment collected information on: physical infrastructure; health human resources; equipment and supplies, referral and record keeping. Information was collected through observation and asking specific questions to relevant staff members at the facility. Human resources data were also collected.

\section{In-depth interviews with managers and service providers}

As the aim of this study was to identity opportunities and challenges for providing round-the-clock safe delivery services from HFWC, so it was considered appropriate to conduct interviews with union-level service providers and upazila and district level program managers. Interviews were conducted with Deputy Director-Family Planning (DDFP), Upazila Family Planning Officer (UFPO), Medical Officer-Maternal and Child Health and Family Planning (MO-MCHFP) and service providers at the union level. Generally, Family Welfare Visitor (FWV) plays key role in providing maternal health checkups and pregnancy related services at the HFWC. Activities of FWVs are supervised by UFPO and MO-MCHFP who report to DD-FP. Therefore, the UFPO and MO-MCHFP, and DD-FP were selected as participants of upazila and district level program managers respectively for this study. 


\section{FINDINGS FROM A SITUATION ANALYSIS}

This section provides a summary of the assessment of 24 HFWCs, focusing on important features of physical infrastructure, health human resources, and gaps in service delivery. The findings present what is actually happening at union level service delivery points in terms of inputs and processes.

\section{Physical infrastructure}

Information was collected on the building, utility, communication and transportation. Not all facilities have a signboard; five HFWCs are yet to have a signboard. Two-thirds of the facilities have a sign announcing that maternal, newborn and child health services are available. There is variation in the number of rooms across facilities. HFWC have a minimum of six rooms: waiting space, pharmacy, FWV room, MA/SACMO room, FPI room, and IUD/menstrual regulation (MR) room. In some HFWCs, there is an examination room, recovery room, storeroom and/or doctor's room. Half of the HFWCs were found to have seven rooms. Currently, there is a maximum of 10 rooms in a HFWC.

Table 3 Physical infrastructure

\begin{tabular}{|l|r|}
\hline Category & Number \\
\hline Has a sign board & 19 \\
\hline Has sign announcing that maternal, newborn and child \\
health services available & 16 \\
\hline Facilities by number of rooms & 3 \\
6-roomed facility & 12 \\
7-roomed facility & 4 \\
8-roomed facility & 2 \\
9-roomed facility & 3 \\
10-roomed facility & 6 \\
\hline Used as delivery room (occasional) & 2 \\
\hline Has rest room with beds & 0 \\
\hline Has pathological service & $\mathbf{2 4}$ \\
\hline N & \\
\hline
\end{tabular}

None of the facilities had the provision for round-the-clock services. Six facilities reported providing delivery services, occasionally. To provide delivery services, the IUD/MR room is used as labor room. There was restroom or recovery room in only two facilities, which have two beds each. None of the facilities reported having a labor ward. None of the facilities had a provision for pathological service (Table 3). 
Two-thirds of the facilities have a storeroom. Not all stores are equipped with necessary furniture. In 14 facilities, the store has a cabinet, and there were shelves in only nine facilities. There was no refrigerator in any storeroom. Overall record-keeping of the store was done systematically. Facilities have a register to maintain daily supplies regardless of the availability of a storeroom. Out of 24 facilities, 22 facilities reported regular updating of stocks of supplies and drugs. A lapse was found in storing stocks by expiration date - only ten facilities reported such a practice (Table 4).

Table 4 Storage system

\begin{tabular}{|l|r|}
\hline Category & Yes \\
\hline Supplies are stored in a separate, safe place & 16 \\
\hline Store has cabinet & 14 \\
\hline Store has shelves & 9 \\
\hline Store has refrigerator & 0 \\
\hline Has register to maintain daily supplies & 22 \\
\hline $\begin{array}{l}\text { Stocks of supplies and drugs updated regularly } \\
\text { (monthly) }\end{array}$ & 22 \\
\hline Stocks stored by expiration date & 10 \\
\hline N & $\mathbf{2 4}$ \\
\hline
\end{tabular}

Table 5 shows that only one facility had piped water. Ten facilities did not have a water supply either a through tube well, or through piped water. Half of the facilities reported the availability of electricity. Eight facilities had a generator while two of them had the generator functional. The major problems for the IUD/MR room lies with the supply of electricity; only two facilities reported using generator as an alternate source of electricity in IUD/MR room (Table 5). The reason for not using a generator is the expenditure related to fuel. The facilities that reported using a generator receive the fund for fuel from the Upazila Parishad. For quality services, it is necessary to ensure adequate and uninterrupted light either through a generator or through solar panel.

None of the facilities has a modern communication system with land phone or dedicated mobile phone. There was no provision of an ambulance at the facilities. HFWCs should have a locallymanaged transportation system to ensure timely referral of complicated patients. The waiting space in all facilities had chairs and/or benches. There was electric fan at the waiting space in all the facilities that had electricity. Only one-fourth of the facilities had a separate toilet for women in the waiting room (Table 5). 
Table 5 Utilities

\begin{tabular}{|c|c|}
\hline Category & Yes \\
\hline \multicolumn{2}{|l|}{ Water supply } \\
\hline Facility has water supply & 14 \\
\hline Facility has tube well & 13 \\
\hline Tube well water supplied by motor & 6 \\
\hline Facility has piped water & 1 \\
\hline \multicolumn{2}{|l|}{ Electricity } \\
\hline Facility has electricity supply & 12 \\
\hline Facility has a generator & 8 \\
\hline In working condition & 2 \\
\hline \multicolumn{2}{|l|}{$\begin{array}{l}\text { Power supply in absence of electricity in IUD/MR } \\
\text { room }\end{array}$} \\
\hline Generator & 2 \\
\hline Candle & 2 \\
\hline Torch with battery & 5 \\
\hline Charger light & 5 \\
\hline \multicolumn{2}{|l|}{ Waiting space } \\
\hline Has chairs/benches in waiting space & 24 \\
\hline Has electric fan & 12 \\
\hline Has separate toilet for women & 7 \\
\hline Has communication system with land/mobile phone & 0 \\
\hline Has ambulance & 0 \\
\hline $\mathrm{N}$ & 24 \\
\hline
\end{tabular}

The number of toilets ranged between 2 to 3 in the HFWCs. Ideally, there should be four toilets in the facility, specifically for delivery/IUD room, service provider, female clients, and male clients. Out of 24 facilities, 20 facilities had a toilet in the waiting space for patients. All of these toilets were found with a lock; 14 were clean while only eight had water. The toilet for the service provider was in the best condition. Of 19 facilities which had a separate toilet for service providers, toilets were clean in 15 facilities and 10 had water. In 17 facilities, there was a toilet for the IUD room and onethird of them were clean with water. A majority of the toilets had a source of natural light or electricity (Table 6). 
Table 6 Toilet condition

\begin{tabular}{|l|r|r|r|}
\hline Characteristics & Waiting space & IUD room & $\begin{array}{r}\text { Service } \\
\text { provider's room }\end{array}$ \\
\hline Have toilet & $\mathbf{2 0}$ & $\mathbf{1 7}$ & $\mathbf{1 9}$ \\
\hline Clean & 14 & 6 & 15 \\
\hline Water & 8 & 5 & 10 \\
\hline Light & 18 & 12 & 19 \\
\hline Ventilation & 16 & 14 & 16 \\
\hline Door with lock & 20 & 14 & 18 \\
\hline N & 24 & 24 & 24 \\
\hline
\end{tabular}

Table 7 shows that in six facilities, there was room for conducting delivery services. Of them, three HFWCs had separate labor room, and in the remaining three HFWCs, the IUD/MR room was converted as labor room. Among the six HFWCs that had a labor room, only two had a postdelivery rest room. In one of these HFWCs, despite having no midwifery training, FWV conducted deliveries. Table 7 also shows that among these six HFWCs, four FWVs received six-month midwifery training and one FWV was trained on EOC for one month.

Table 7 Status of HFWCs conducting delivery services

\begin{tabular}{|l|r|}
\hline Category & Number \\
\hline Delivery room & \\
\hline Separate labor/delivery room & 3 \\
\hline Converted labor/delivery room & 3 \\
\hline Have post-delivery rest room & 2 \\
\hline Training received by FWV & 4 \\
\hline 6-month midwifery training & 1 \\
\hline 1-month EOC training & 6 \\
\hline N & \\
\hline
\end{tabular}

HFA also revealed that although these six HFWCs were strengthened with the necessary equipment and drugs for normal delivery services, deliveries were conducted at these facilities at the initiative of service providers, not systematically. Systemic linkage with the outreach services was also missing. Alarmingly, there was no system of supervising the deliveries conducted at those facilities. The number of reported deliveries conducted was grossly insufficient. Often, FWVs pass a week without conducting any delivery. It was also found during the assessment that the delivery service was being provided in an irregular fashion, catering to the convenience of service providers rather than the needs of clients. There was no systematic documentation of delivery services as there was no delivery register. The way these HFWCs had been strengthened fell far short of producing expected outcomes and there was no lesson from these HFWCs which can be used for designing programs at the national level. 


\section{Human resources}

Analysis of information on the availability of service providers (MO, SACMO/MA, FWV) gives a mixed condition in terms of headcounts. The status of human resources in terms of the availability of doctor was poor. Only half of the doctors were posted against the available position, and of those, only half of them were present on the day of assessment. The headcount of service providers indicate the full availability of FWVs, where all facilities had the FWV in place. Not all facilities had a SACMO/MA in place. Yet, in eight facilities, the vacant posts of SACMO/MA are required to be filled. The attendance of FWV and SACMO was satisfactory, as only one FWV and one SACMO were reported absent on the day of assessment.

Regarding indirect providers and support staff, however the situation is worse. Nationally, there was sanctioned post of pharmacist in one-fifth of the HFWCs. Only three facilities reported the availability of pharmacists. One-third of the facilities had a MLSSs available (8 against 24). Nineteen out of 24 facilities reported the availability of aya or delivery assistant, while two were absent on the day of assessment (Table 8).

Table 8 Human resources situation

\begin{tabular}{|l|r|r|r|}
\hline Category & Sanctioned post & $\begin{array}{r}\text { Available against } \\
\text { post }\end{array}$ & $\begin{array}{r}\text { Present on the day } \\
\text { of assessment }\end{array}$ \\
\hline MO (doctor) & 20 & 9 & 4 \\
\hline SACMO/MA & 24 & 16 & 15 \\
\hline FWV & 24 & 24 & 23 \\
\hline FPI & 24 & 17 & 11 \\
\hline Pharmacist & 20 & 4 & 3 \\
\hline Aya & 24 & 19 & 17 \\
\hline MLSS & 24 & 8 & 8 \\
\hline Security guard & 21 & 14 & 13 \\
\hline N & & 24 & \\
\hline
\end{tabular}

Currently, as there is no post of cleaner for HFWCs, toilets are kept clean at the aya's initiative (not shown in the table). It is necessary to create a post of a cleaner if HFWCs start to provide delivery services, for both keeping the toilets and labor room clean and hygienic, and ensuring proper waste management.

Human resources situation in terms of training was not satisfactory. Thirteen of the FWVs were trained on midwifery - 10 FWVs were trained for six months and the remaining 3 FWVs for one month. Less than one-fourth of the FWVs had life-saving skills (LSS) training. Among other training, 15 FWVs were trained on infection prevention. Among the available SACMOs, 11 were trained on IMCI and 6 had training on infection prevention. None of the FWVs and SACMOs had newborn care training (Table 8a). 
Table 8a Training situation

\begin{tabular}{|c|c|c|c|c|}
\hline \multirow[t]{2}{*}{ Training } & \multicolumn{2}{|c|}{ FWV } & \multicolumn{2}{|c|}{ SACMO/MA } \\
\hline & Available & Trained & Available & Trained \\
\hline 1-month midwifery & \multirow{7}{*}{24} & 3 & \multirow{7}{*}{16} & - \\
\hline 6-month midwifery & & 10 & & - \\
\hline 2-week LSS & & 1 & & - \\
\hline 4-week LSS & & 4 & & - \\
\hline $\mathrm{IMCl}$ & & - & & 11 \\
\hline Newborn care & & - & & - \\
\hline Infection prevention & & 15 & & 6 \\
\hline $\mathbf{N}$ & \multicolumn{4}{|c|}{24} \\
\hline
\end{tabular}

To ensure the regularity of services, residential quarters for staff have been constructed. All HFWCs had residential quarters for their service providers. The location of residential quarters varies depending on the physical structure of the HFWCs. Generally, two- and three-storied HFWCs have residential quarters in the upper floor of the facility building while one-storied HFWCs have the residence in a separate one-story building in the compound.

Table 9 Accommodation

\begin{tabular}{|c|c|}
\hline Accommodation & Number \\
\hline Residence in the facility building & 15 \\
\hline $\begin{array}{l}\text { Residence in separate 1-story building in } \\
\text { compound }\end{array}$ & 9 \\
\hline Has boundary wall & 4 \\
\hline Piped water & 6 \\
\hline Electricity & 12 \\
\hline \multicolumn{2}{|l|}{ Number of rooms } \\
\hline 2 rooms & 3 \\
\hline 3 rooms & 21 \\
\hline \multicolumn{2}{|l|}{ Number of toilets } \\
\hline 1 toilet & 9 \\
\hline 2 toilets & 15 \\
\hline Toilet inside & 20 \\
\hline \multicolumn{2}{|l|}{ Residential status } \\
\hline MO residential & 0 \\
\hline FWV residential & 6 \\
\hline SACMO residential & 4 \\
\hline $\mathbf{N}$ & 24 \\
\hline
\end{tabular}


Of 24 HFWCs, 15 had a residence in the facility building and the remaining 9 had a residence in separate one-storied building in the compound. Only four residences had a boundary wall. There are two types of residence in terms of the number of rooms, other than the kitchen and toilet. Out of 24, 21 facilities had three-roomed residence while other 3 facilities had a two-roomed residence. Most of the residences had the toilet inside the building. Only six FWVs were found to be residential. Lack of the basic utilities at the residence may be one of the reasons for the service providers not to stay at the residence. One-fourth of the residences had piped water and half of the residences had electricity (Table 9).

\section{Gaps in service delivery}

Although one-fourth of the facilities reported providing normal delivery services occasionally, none of them maintained partographs. MR services are supposed to be provided from all facilities; yet six facilities do not perform MR services.

Table 10 Services and Referral

\begin{tabular}{|c|c|}
\hline Category & Yes \\
\hline \multicolumn{2}{|l|}{ Services } \\
\hline Provide normal delivery services (occasional) & 6 \\
\hline Maintain partograph & 0 \\
\hline Perform MR services & 18 \\
\hline \multicolumn{2}{|l|}{ Infection prevention management } \\
\hline Instrument processing through chlorination & 17 \\
\hline Instrument processing through autoclave (mini) & 6 \\
\hline Waste management through incinerator & 11 \\
\hline Waste management through separate bin for liquid/solid/sharps & 2 \\
\hline Provide essential newborn care ${ }^{*}$ & 0 \\
\hline Provide ORT (Oral Rehydration Therapy) & 13 \\
\hline \multicolumn{2}{|l|}{ Referral } \\
\hline Refer an emergency case & 16 \\
\hline \multicolumn{2}{|l|}{ Where the clients are referred } \\
\hline Upazila Health Complex & 14 \\
\hline Sadar hospital & 1 \\
\hline Private provider & 1 \\
\hline Service provider escorts the referred client to the higher facility & 2 \\
\hline $\mathrm{N}$ & 24 \\
\hline
\end{tabular}

${ }^{*}$ Resuscitation, umbilical cord care, sepsis management, low birth weight management 
Table 10 shows overall management of infection prevention in terms of instrument processing and waste management. In 17 facilities, instruments were sterilized mainly through chlorination. Infection prevention through mini-autoclave was maintained in only six facilities. Half of the facilities reported using an incinerator as part of waste management. Waste management through separate bins for liquid, solid, and sharp items was rarely practiced (only two facilities). All these results highlight the need for equipment and training on infection prevention and waste management.

Essential newborn care (i.e., resuscitation, umbilical cord care, sepsis management, low birth weight management) is not provided at any of the facilities. Half of the facilities provide some curative care for diarrheal disease. At present, a majority of the service providers refer emergency clients to higher-level facilities. Upazila Health Complex is the facility where almost all referral cases are sent. One service provider reported sending referral cases to private provider. It is not common among service providers to escort the referred client to the higher facility - only two providers reported such service (Table 10). 


\section{FINDINGS FROM IN-DEPTH INTERVIEWS}

In-depth interviews were conducted at two levels: service provider and manager. Twelve FWVs were interviewed to know their views on the programmatic opportunities and challenges to strengthen HFWCs for providing round-the-clock safe delivery and newborn care services. Similarly, a total of 12 managers, which include DD-FP, UFPO and MO-MCHFP, were interviewed. The discussions that follow will highlight on the key findings from those in-depth interviews.

\section{A. Experience and opinions of FWVs}

\section{Recruitment and replacement}

Interviews with the FWVs revealed that none of them was recruited after 1992. Half of the FWVs were recruited in 1988. Only one FWV reported 1992 as her first joining the service. The remaining five FWVs joined between 1979 and 1985. Out of 12 FWVs, seven will retire before 2020. The results demonstrate a long pause in the recruitment of FWVs which require special attention of policy makers and program managers.

All FWVs received different professional trainings during their service, but none received any training on newborn care and IMCI. All but two FWVs reported receiving midwifery training.

\section{Residential status}

Only three FWVs were found to be residential at the facility. Those FWVs who are not residential reported that it takes a maximum of 30 minutes to come to the HFWC from their residence, except one FWV who mentioned one hour. Motorized vehicle was mentioned as the main transport.

The accommodation is not free. FWVs need to pay to stay at the residential quarter, which discourages them to stay there. Rent is deduced from the salary. There were extremely inadequate utilities available at the residence. Most of the residences do not have piped water, a tube well, or electricity. In some residences, water seeps from the ceiling during rainy days. Some HFWCs do not have the provision of safe drinking water as a few FWVs reported using pond water for cooking and drinking. In one residence, there is solar electricity, but only one bulb is permitted.

\section{Conducting delivery at HFWC}

Ten out of twelve FWVs reported conducting a delivery at client's home in the past three months. It is important to note that, six out of ten FWVs, who reported conducting delivery at client's home, performed delivery at the facility too. Four other FWVs did not conduct any delivery at the facility primarily due to the lack of support staff and absence of necessary equipment and medicines at the facility. For providing delivery services at the HFWC, they suggested creating an appropriate environment with additional human resources like a nurse, aya and cleaner, sufficient equipment and medicine, and adequate security. They also emphasized the posting of a doctor for supervising safe delivery services.

There was no diversity of opinion among the FWVs on strengthening the HFWC for providing delivery services as all of them have expressed their commitment to ensure safe delivery from the 
HFWC with the purpose to reduce maternal and newborn deaths. FWVs mentioned several reasons for justifying strengthening of HFWC to provide delivery services. First, they have the professional knowledge on pregnancy and delivery and now they need basic EOC or midwifery training to conduct delivery at the HFWC, which will relieve the traditional dai from conducting unsafe delivery at home. Even if delivery is conducted at the home by SBAs, the home environment is not clean or hygienic. FWVs also mentioned that traveling a long distance to the Upazila Health Complex or District Hospital often worsens the condition of pregnant women while going to union HFWC for delivery services will lessen the difficulties related to the distance, transportation and cost. All FWVs were unequivocal that the poor will benefit the most if delivery service is provided at the union HFWC.

\section{How to strengthen HFWC for providing delivery services}

Due to their long experience, FWVs were well aware of the needs to strengthen the HFWC for providing delivery services and identified the required inputs. All of them strongly advocated for the round-the-clock delivery services at the HFWC with a modern management system. Broadly, they focused on five areas.

- Physical infrastructure. Infrastructure is in a poor condition. Repairing building and upgrading the building with more rooms must be immediately dealt with. The need for renovating the HFWC with separate delivery room was highlighted. It is also necessary to establish a 'maternal and child health ward' with beds. Supply of running water inside the facility and uninterrupted supply of electricity was another key requirement. A drainage system must be in place. Another suggestion was to improve the condition of toilets and ensure separate toilet for female service recipients. There should be appropriate residential arrangement with basic amenities. HFWC needs boundary wall as a means to ensure security of the campus and to display the status of hospital. A collapsible gate is required at the entrance. Some beautification like making a garden in the yard is also suggested.

- Human resources. FWVs were specific in recommending the necessary human resources. They focused on three issues: filling vacancies, increasing manpower, and recruiting a medical officer trained in gynecology. FWVs also felt the need to ensure the availability of service providers at the facility for round-the-clock services. They also emphasized on the supportive supervision by MO-MCHFP. Through supervision and advanced training, existing services can be improved. Without the night guard, FWVs are anxious about staying at the residence.

- Equipment and drugs. Fully-equipped delivery room and necessary drugs must be ensured for providing delivery service. Furniture is required for the post delivery room, doctor's room, and store. Medicine should be supplied on the basis of needs.

- Transportation. Appropriate transportation from the community to HFWC and from HFWC to Upazila Health Complex needs to be arranged. Moreover, pregnant women should know the cell number of service providers for communicating with them in case of emergency. 
- Community participation. Cooperation from community people and assistance from local level leaders are necessary for mobilizing resources and ensuring accountability of service providers.

\section{Additional human resources}

The key barrier identified to provide round-the-clock services is the shortage of human resources and absence of necessary staff mix for transforming the HFWC from an outreach center to a hospital. Existing human resources is not adequate for performing delivery services at the HFWC. Analysis of in-depth interviews with FWVs indicates the necessity of some additional human resources to perform delivery services. FWV is the key provider for delivery services at the HFWC. Number of FWV per HFWC should be increased from one to two along with corresponding increase in support staff. The existing FWV is overburdened as she needs to go to satellite clinics two days per week, and in some cases she needs to give service at another HFWC, which makes it impossible to provide 24-hour services by only one FWV. First, an additional FWV trained in midwifery with an aya is required for providing 24-hour service. Creating the post of a nurse and a cleaner at the HFWC was strongly suggested. Some suggested for recruiting two nurses upon creating post. It is also necessary to recruit MLSS (peon). Existing post of pharmacist and night guard should be filled in immediately. The need for posting a doctor trained in gynecology was particularly emphasized.

\section{Problems faced by FWVs in performing job}

FWVs identified several difficulties at both the supply and demand side which hinders them in performing their responsibilities effectively. Problems on the supply side are:

- Lack of proper services like delivery and newborn care.

- Absence of water supply and uninterrupted electricity.

- Shortage of medicines.

- Inadequate service providers.

- Limited opportunity for advanced training.

- Insecurity of staying at the facility.

- Limited amenities at the residential facility.

- Client load.

At the demand side, transportation/communication problem, religious conservatism, and lack of awareness are the barriers clients face to access services from the HFWC.

\section{How to strengthen HFWC for providing newborn care services}

All FWVs strongly recommended strengthening HFWC for providing newborn care services. It is necessary to provide newborn care services along with normal delivery from HFWC to the local population (who are mostly poor) otherwise newborn babies need to be taken to upazila hospital, traveling a long distance and losing valuable time to save life. Currently, there is no scope for providing newborn care services from the HFWC, and there is a great difficulty to refer newborn to upazila hospital in case of complications. The respondents identified some requirements on human resources, equipment and drugs to strengthen HFWC for providing newborn care services. 
- Infrastructure. A separate child ward with beds for newborns is needed. There should be a separate consultation room for the doctor.

- Human resources. A pediatrician is needed. A post of nurse needs to be created. Existing service providers (SACMO/MA/FWV) should be trained on newborn care.

- Equipment and drugs. Primarily, newborns with breathing problem come to HFWC for which necessary equipment and medicines do not exist. Equipments for neonatal resuscitation, oxygen cylinder, ambu bag, nebulizer machine, and sucker machine are the basic requirements for providing newborn care services. Medicines for treating pneumonia, diarrhea and sepsis are needed.

\section{Motivation}

Most of the FWVs were not satisfied with the salary they get from the government in the context of price-hike of essential daily goods. FWVs expressed their dissatisfaction over the expenditure incurred while going to satellite clinics. Each FWV needs to conduct eight satellite clinics in a month. Some of them mentioned that they go to satellite clinics at their own expense. They opined that there should be some allowance for visiting satellite clinics. In some cases, the FWV is held responsible for two HFWCs due to some emergencies. In such cases of additional responsibilities, there should be some monetary incentive.

All FWVs agreed with the idea to give performance bonus to service providers for increasing their motivation and improving quality of services. But, they were divided on the frequency of incentives. Half of them suggested providing incentive annually, three FWVs advised two times a year and remaining three of them suggested incentive monthly.

\section{B. Experience and opinions of managers}

All 12 managers recommended strengthening HFWCs for delivery services. There were several reasons for their strong recommendation. First, poor people will get delivery and newborn care service without cost and barrier related to distance. It will increase awareness among the community about the necessity of having child births at the facility. On the supply side, strengthening HFWCs for providing delivery services will address four health system functions:

- Pressure will be reduced from higher-level facilities

- Skills of CSBA and FWV will be optimally utilized

- Round-the-clock delivery services (i.e., hospital) will be available in the community

- Functional referral system will be established.

\section{How to strengthen HFWC for providing delivery services}

Decentralization of services will be a useful instrument for implementing suggested changes in infrastructure and recruitment of additional human resources. Recommendations made by the managers are nearly similar to those of FWVs. The managers suggested for the round-the-clock delivery services at the HFWC with an effective referral mechanism. If two FWVs are posted and 
vacant posts are filled then it is possible to provide round-the-clock services. Broadly, they emphasized five areas.

- Physical infrastructure. The facility needs to be remodeled with a well-equipped, separate labor room and a post-operative room with a minimum of four beds. It is also necessary to ensure the supply of running water inside the facility and uninterrupted supply of electricity. If renovated and basic utilities are ensured at the residential quarters, service providers will be encouraged to stay at the residence. In addition to the quarters for SACMO and FWV, residential facility must be built for the doctor. There should be boundary wall surrounding the campus.

- Human resources. Regarding human resources, the managers emphasized filling vacancies and increasing manpower. They advised to utilize SBAs in a union by rotation. With a mix of FWV and SBA, round-the-clock delivery services can be arranged. On the other hand, if possible, an additional FWV can be posted. Providing an additional delivery assistant (aya) is another requirement. SACMOs, who are willing to provide delivery services, can be given midwifery training. Filling the vacancies of supervisory staff at the upazila level is likely to ensure proper monitoring and supervision at the union level.

- Demand-side financing. Financial assistance should be provided to the poor women for defraying the cost of transportation and medicine. In case of emergency, a system for community van to take the patient to higher-level hospital must be in place.

- Referral. Referral chain with upazila and district must be established and proper follow up needs to be ensured. In addition, increasing coordination with NGOs at field level will enhance coverage and ensure timely referral.

- Community participation. Developing a cadre of community volunteers and mobilizing resources are two areas for which community people can be involved. Community involvement can also be useful tool for creating awareness among people. The Union Parishad can mobilize resources locally for meeting emergency needs or for maintenance of the facility.

\section{Additional human resources}

None of the 12 managers found the existing provision of human resources adequate for performing delivery services at the HFWC. Additional human resources for delivery services as identified by the managers are FWV, aya, and nursing attendants. Analysis of data revealed that 10 out of 12 managers strongly recommended for recruiting an additional FWV trained on midwifery and the existing FWV should receive midwifery training too. Other two respondents opined that if recruiting an additional FWV is not possible immediately, six-month midwifery training should be provided to the existing FWVs in the interim period. As a whole, two packages of human resources were suggested.

- For providing round-the-clock services from HFWCs, three sets of FWVs/midwives with nursing attendant/aya will be required. 
- Another group of managers opined for a staff mix of two FWVs, two ayas and one doctor for providing round-the-clock services from HFWCs. If possible, 1-2 nursing attendants can be recruited. In addition, other provider and staff must be in place.

Service providers must stay at the facility, and will provide services by rotation. There should be night guard for ensuring the security of both HFWC and residential quarters.

\section{How to strengthen HFWC for providing newborn care services}

All but one manager recommended strengthening the HFWC for providing newborn care services by reasoning that it is a part of normal delivery to manage newborn complications for saving lives. Moreover, travelling long distances to upazila hospital or district hospital may worsen the condition of the sick, vulnerable newborn. One respondent mentioned the policy related to the lack of availability of a child specialist as a barrier to integrate newborn care services. The respondents, however, identified some requirements on human resources, equipment and drugs to strengthen HFWC for providing newborn care services.

- Providing training on newborn care and IMCI to all SACMOs will be the first step toward providing newborn care services. Same training should be given to the FWVs too. It was strongly suggested for exempting FWVs from the satellite clinic services, and vaccination campaign.

- Postnatal care for a minimum three times ( 6 hour, 6 days, 6 week) was suggested. Fieldworkers must visit within seven days after delivery at newborn's home for umbilical cord care and early detection and management of sepsis as well counseling on exclusive breastfeeding.

- Another recommendation was to develop a separate ward for newborns equipped with oxygen cylinder, incubator, sucker machine and other necessary instruments for essential newborn care. In addition, supply of necessary medicines must be ensured.

- It is also necessary to provide transport allowance to caregivers of newborn for seeking care from the facility.

\section{Motivation}

- There should be incentives for providing services round-the-clock. Incentives can be provided for staying at the facility.

- House rent should not be deducted for staying at the facility.

- Performance-based incentive is necessary, which can be given based on periodic targets (monthly or quarterly) or according to number of services. Proportion of basic salary can be given as an incentive against periodic targets, e.g., one-month basic salary after three months. Alternatively, a package of incentive is suggested. For example, a total of Tk. 1000 can be given for each delivery, which will be distributed among service providers (doctor: Tk. 500, FWV: Tk 300, and aya: Tk. 200). Some suggested case-based incentive. For each delivery Tk. 
500 and for newborn care Tk. 50 can be given as incentive to the provider. In addition to the service provider, aya and MLSS will receive incentives.

- For improving fieldworkers' performance, a case-based incentive should be in place for making referral.

- The managers also suggested incentive for clients, which will be strictly limited to the first and second delivery of the clients. 


\section{CONCLUSION}

Normal delivery services are provided in a few HFWCs occasionally, but not in a systematic manner. Essential newborn care (e.g., umbilical cord and eye care, temperature maintenance, resuscitation, sepsis management) is not provided from the HFWCs. HFWCs can be strengthened to provide normal delivery and newborn care services, and will not necessarily have the provision to manage critical life-threatening maternal and neonatal complications, for which clients should be referred to higher-level facilities.

Several gaps in the existing capacity of HFWCs for providing round-the-clock delivery services were identified through situation analysis. Necessary inputs are broadly described in three categories: physical infrastructure, human resources, and referral.

\section{Physical infrastructure}

In many cases, infrastructure is in poor condition. There is lack of essential utilities, e.g., supply of water and electricity. Repairing building and upgrading the building with more rooms must be immediately dealt with.

- Existing signboard at the HFWCs does not seem to attract more clients. HFWCs should have a sign with a list of key services including maternal, newborn and child health services and opening and closing time to capture the attention of the local population.

- There is variation in the number of rooms across facilities. HFWC is consisted of a minimum of six rooms: waiting space, pharmacy, FWV room, MA/SACMO room, FPI room, and IUD/MR room. In some HFWCs, there is a recovery room, storeroom, medical officer room and/or examination room. Currently, there is a maximum of 10 rooms in a HFWC. To provide delivery services, IUD/MR room are converted as a labor room. The facility needs to be remodeled by establishing a well-equipped, separate labor room, if HFWC is transformed into a hospital.

- None of the HFWCs reported having a furnished female/labor ward. In only two HFWCs, there is a rest room or post-operative room for IUD/MR/delivery clients. A labor ward with at least two beds is necessary to provide round-the-clock delivery and newborn care services.

- Another recommendation was to develop a separate ward for newborns equipped with oxygen cylinder, incubator, sucker machine and other necessary instruments for essential newborn care.

- Not all facilities have a storeroom. In most cases, stores are not equipped with necessary furniture (cabinet and shelves) either. There was no refrigerator for any storeroom.

- There is no provision for pathological service at the HFWC.

- Yet, many facilities do not have water supply either through tube-well, or through piped water. Indoor supply of water must be ensured before providing delivery services from the 
HFWCs since running water supply is required to maintain hygiene and ensure infection prevention. A drainage system must be in place too.

- Other major problem for HFWC lies with the supply of electricity, which is a critical element for performing delivery services at the facility. Although half of the facilities reported having connection of electricity, only two facilities had the uninterrupted power supply through generator, where the cost of fuel was provided by Upazila Parishad. Mostly, charger light or torch is used as source of light in absence of electricity. It is necessary to ensure uninterrupted electricity either through generator or through solar panel.

- There are not enough toilets at the HFWCs. The number of toilets ranges between 2 to 3 per HFWC. Ideally, there should be four toilets in each HFWC, specifically for waiting space, IUD/delivery room, and service provider. It was strongly recommended to ensure separate toilet for female service recipients and improve the condition of toilets. All toilets should have a lock, water and proper ventilation.

- All HFWCs have residential quarters for service providers (SACMO and FWV) in a way to ensure the regularity of services. But, non-resident status of service providers is a persistent problem. Like the facility building, there is lack of essential utilities, e.g., supply of water and electricity at the residential quarters. If renovated and basic utilities are ensured at the residential quarters, service providers will be encouraged to stay at the residence. In addition to the quarters for SACMO and FWV, a residential facility must be built for the doctor.

- HFWC needs a boundary wall as a means to ensure security of the campus and to display the status of hospital. Collapsible gate is required at the entrance. There should be a night guard for ensuring the security of both HFWC and residential quarters. Some beautification like making a garden in the yard is also suggested.

\section{Human resources}

The key barrier identified to provide round-the-clock services is the shortage of human resources and absence of necessary staff mix for transforming the HFWC from an outdoor center to a hospital. Existing human resources is not adequate for performing delivery services at the HFWC, neither for providing round-the-clock services. Situation analysis emphasized the necessity of several additional human resources to perform round-the-clock delivery services.

- FWV is the key provider for delivery service at the HFWC. The existing FWV is overburdened as she needs to go to satellite clinics two days per week, and in some cases she needs to give service at another HFWC, which makes it impossible to provide 24-hour services by only one FWV. It was strongly recommended to recruit an additional FWV trained in midwifery, and the existing FWV should receive midwifery training too.

- Number of FWV per HFWC should be increased from one to two along with corresponding increase in support staff. An additional FWV trained in midwifery is required for providing a 24-hour service. If recruiting an additional FWV is not possible immediately, existing skilled birth attendants (SBAs) can be utilized by rotation in the interim period. With 
a mix of FWV and SBA, round-the-clock delivery services can be arranged. Providing additional delivery assistant (aya) is another requirement.

- A staff mix of two FWVs, two ayas and one doctor is required for providing round-the-clock services from HFWCs. If possible, two nursing attendants can be recruited upon creating post. In addition, other provider and staff must be in place.

- Human resources situation in terms of availability of doctor at the HFWC is poor. There is large number of vacant posts for Medical Officer. Even worse, only half of the doctors were posted against the available position. The need for posting a doctor trained in gynecology was particularly emphasized.

- Regarding indirect providers and support staff, the situation is worse. An insufficient number of posts were created for 'pharmacist'. One in every six HFWC reported having a pharmacist position. In one-third of the facilities, MLSSs were available. The post of pharmacist should be created immediately at every HFWC.

- Currently, as there is no post of cleaner for HFWC, toilets are kept clean at the aya's initiative. It is necessary to create a post of a cleaner if HFWC starts to provide delivery services.

- Human resources situation in terms of training is not satisfactory. Some FWVs received training on midwifery. None of the FWVs received training on newborn care and IMCI. A few SACMOs were trained on IMCI.

- It is observed that infection prevention through autoclave and waste management through separate waste bins for liquid, solid, and sharp are not usually maintained at the HFWCs, for which necessary training on infection prevention should be given to service providers and concerned support staff.

- Filling in the vacancies of supervisory staff at the upazila level is likely to ensure proper monitoring and supervision at the union level.

- Service providers must stay at the facility, and will provide services by rotation.

\section{Motivation}

- There should be incentives for providing services round-the-clock at the HFWCs. House rent should not be deducted for staying at the facility.

- Performance-based incentive is necessary, which can be given based on periodic targets (monthly or quarterly or half-yearly) or according to number of services. Proportion of basic salary can be given as incentive against periodic targets, e.g., one-month basic salary after three months. Alternatively, for each delivery Tk. 500/1000 can be given as incentive to the delivery team and for newborn care Tk. 50 to the provider. 
- Each FWV needs to conduct eight satellite clinics in a month, and often they go to satellite clinic at their own expense. There should be some allowance for visiting satellite clinics.

- For improving fieldworkers' performance, a case-based incentive should be in place for making referral.

\section{Referral}

- There should be specific direction on where to refer pregnant woman if complications identified at the HFWC. Specifically, who will be the staff at Upazila Health Complex to whom FWV can refer complicated cases, provided the dual management at Upazila Health Complex. Generally, FWV refers complicated cases to MO-MCHFP, but this medical officer is not capable of attending those cases. Linkages should be developed with Upazila Health Complex and District Hospitals for referring complicated cases with a uniform guideline for 'health' and 'family planning' directorates.

There are clearly many issue associated with the recommendations for improving delivery and newborn care. Issues of financing and human resources appear to be paramount. It is unlikely that all the facilities will ever have the status of local hospital as staff appear to desire, but clearly improvement in the full range of requirements would seem to be a warranted investment. 


\section{Population Council}

www.popcouncil.org

South \& East Asia - Bangladesh Office

House CES (B) 21, Road 118

Gulshan, Dhaka 1212, Bangladesh

Phone: 8802-8821227, 8826657

Fax: 8802-8823127

Email: info.bangladesh@popcouncil.org 